\title{
Outcome of toxic megacolon during pregnancy
}

\author{
Carl Chartrand-Lefebvre, BSc, Jacques Heppell, MD, Claude Potvin, MD, \\ RICHARD CLERMONT, MD, ALFONS POMP, MD
}

\begin{abstract}
Two patients with ulcerative colitis required subtotal colectomy and ileostomy for toxic megacolon during pregnancy. Subsequently, a mucosal proctectomy with ileal pouch-anal anastomosis was performed. These two patients who avoided permanent ileostomies were able to carry normal pregnancies and deliver normal infants. These two cases illustrate the clinical features and the favorable outcome of surgical treatment. Can J Gastroenterol $1990 ; 4(0): 230-234$
\end{abstract}

Key Words: Complications of pregnancy, Ileal pouch-anal anastomosis, Toxic megacolon, Ulcerative colitis

\section{Evolution du mégacôlon toxique en grossesse}

RESUME: Deux patientes ont subi une colectomie sub-totale avec iléostomie en urgence pour colite ulcéreuse compliquée de mégacôlon toxique durant la grossesse. Une chirurgie de reconstruction sous forme de réservoir iléal avec anastomose iléo-anale a été pratiquée ultérieurement. Par la suite, tout en évitant l'iléostomie permanente, les deux malades ont pu avoir une grossesse normale et mettre au monde deux enfants normaux. Ces deux cas illustrent les manifestations cliniques et le résultat favorable de notre traitement chirurgical.

U LCERATIVE COLITIS FREQUENTLY begins in early adult life and therefore may occur during pregnancy. The symptoms of colitis can usually be controlled by conventional medical treatment. Surgical intervention for toxic megacolon during pregnancy is uncommon and was initially reported with high fetal and maternal mortality (1). The authors' operation of choice for toxic dilation of the colon is a total colectomy without proctectomy. Leaving the rectum in place permits, in a carefully selected group of patients, the restoration of intestinal continuity and continence by means of a mucosal

The Department of Surgery and Gastroenterology, Hôtel-Dieu de Montréal, Université de Montréal, Montréal, Québec

Correspondence and reprints: Dr Jacques Heppell, Hôtel-Dieu de Montréal, 3840 St-Urbain, Montréal, Québec H2W IT8. Telephone 843-2611 ext 4945, Fax 843-2704

Received for publication June 13, 1990. Accepted June 25, 1990

proctectomy and endorectal ileoanal anastomosis with an ileal reservoir. Two cases of pregnant patients on whom emergency colectomy was neces. sary because of toxic megacolon are reported. These patients later under. went a restorative proctocolectomy and were eventually able to carry a pregnancy to term and deliver healthy infants.

\section{CASE ONE}

A 26-year-old pregnant woman had a history of increased frequency of stools with passage of blood and mucus since the beginning of pregnancy. A proctoscopic examination was suggestive of nonspecific inflammatory bowel disease. The patient was 14 weeks preg. nant when she presented with severe abdominal pain in the right lower quad. rant with nausea and vomiting. Physical examination revealed localized guarding with rebound tenderness. Bowel sounds were diminished. An ultrasound examination showed a normal fetus. At another institution, the patient underwent an appendectomy through a McBurney incision. The ap. pendix was normal but the large and small intestine were dilated. Postoperatively she received blood transfusions. intravenous hydrocortisone and cefoxitin. She showed progressive abdominal distension and increased 


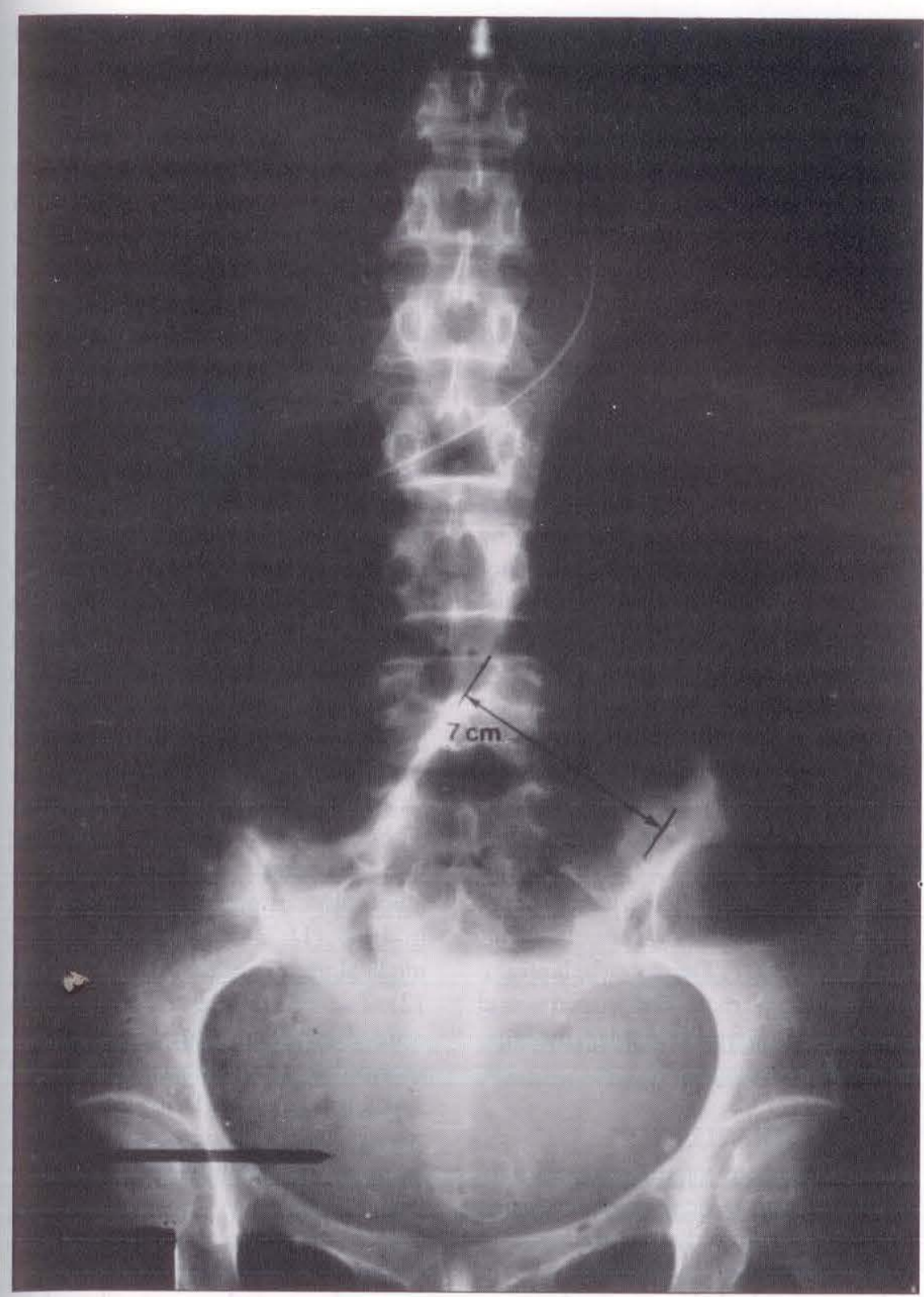

Figure 1) Plain abdominal $x$-ray reveals distended transverse and right colon. Transverse diameter is $7 \mathrm{~cm}$ crossing the midline. A fetus of 15 weeks is identified

leukocytosis. Because of persistent small bowel and colonic distension she was transferred to the authors' institution four days later.

On arrival, the patient complained of diffuse abdominal pain. She was afebrile and her pulse rate was 80 beats/min. An abdominal examination revealed massive abdominal distension with an infected appendectomy wound. Bowel sounds were absent. A proctoscopic examination revealed ulcerated hemorrhagic mucosa with pus and blood. A flat plate of the abdomen revealed a dilated transverse colon (14
A total colectomy with an ileostomy was performed. The histopathological examination revealed a diffuse ulcerative colitis with dilation and perforation of the transverse colon. The postoperative period was complicated by wound infection and allergic rash secondary to antibiotics. Twenty days after surgery, a dilation and curettage were necessary because of fetal death in utero.

The patient recovered completely and nine months later mucosal proctectomy with ileal ' J' pouch anastomosis was performed without complication. The diverting ileostomy was closed three months later. The patient had perfect continence with four to six bowel movements per day. She was employed full-time and had no limitation in activities. She became pregnant 39 months following the ileostomy closure. The prenatal period was uneventful. After the second trimester she noted a slight increase in daytime and nocturnal stool frequency as well as occasional involuntary passage of stools during micturition after the 28 th week of gestation. At term, labour was induced and a healthy $3000 \mathrm{~g}$ female was delivered vaginally. A mediolateral episiotomy was performed and no obstetrical complication occurred. After pregnancy, stool frequency returned to normal and stool continence remained excellent.

\section{CASE TWO}

A 29-year-old pregnant woman was admitted in her 15th week of gestation because of diarrhea, rectal bleeding and tenesmus. She had had two spontaneous abortions previously without relation to gastrointestinal problems. A diagnosis of ulcerative proctitis had been made two weeks prior to admission. Cortisone enemas were discontinued a week prior to admission because of an absence of clinical improvement. On initial examination, the patient appeared pale, asthenic and dehydrated. Abdominal examination revealed tenderness in the left lower quadrant, without distension. Erythema nodosum was apparent in the lower extremities. The cervix was closed. Ultrasound examination re- 
vealed a viable fetus on the uterine posterior wall, with a biparietal diameter of $34 \mathrm{~mm}$ and a normal amniotic fluid volume. The patient received hydrocortisone intravenously with diphenoxylate (Lomotil; Searle) and iron sulphate orally. During the next three days the number of stools decreased; however abdominal distension and increasing abdominal pain associated with fever was noted. The patient was transferred to the authors' institution.

Upon arrival, her pulse rate was 102 beats/min and the abdomen was distended and diffusely tender; however there was no clear evidence of peritoneal irritation. A proctoscopic examination revealed linear ulcerations with blood and purulent exudate. Hemoglobin was $8.3 \mathrm{~g} / \mathrm{L}$, hematocrit $24.8 \%$, and white cell count $10,100 \mathrm{~mm}^{3}$ (stab $40 \%$ ). Blood and fecal cultures were negative and urinalysis was normal.

Intensive measures to improve the general condition of the patient were instituted including blood transfusion, intravenous hydrocortisone, antibiotics and nasogastric intubation. An erect, abdominal, plain $\mathrm{x}$-ray with a protective shield over the pelvis revealed a distended transverse and right colon. The maximal diameter of the transverse colon was $8 \mathrm{~cm}$ (transverse diameter 7 $\mathrm{cm}$ crossing the midline). There was no free air and the fetus was identified in the pelvis (Figure 1).

Because of slight clinical improvement medical treatment was continued for $24 \mathrm{~h}$. However, the second day following admission progressive distension of the abdomen with no peristalsis and deterioration of general condition mandated surgical intervention.

When the peritoneum was entered, a dilated transverse and right colon was identified. There was no evidence of perforation. The uterus was at the level of the sacral promontory. A total colectomy with an ileostomy were performed. A histopathologic examination of the specimen confirmed the diagnosis of ulcerative colitis with dilation. The patient made an uneventful recovery with parenteral nutrition, intravenous hydrocortisone and antibiotics. Eleven days after surgery, ultrasound of the pelvis showed a nor- mal fetus with a biparietal diameter of $38 \mathrm{~mm}$. After adequate counselling with a dietitian and a stomotherapist the patient was discharged. She completed her pregnancy to term and delivered a healthy girl.

Thirty-seven months later the patient underwent a mucosal proctectomy with an ileal pouch-anal anastomosis. The diverting ileostomy was closed three months later. Two months after this closure, an ischiorectal abscess was drained. A fistula communicating with the posterior wall of the reservoir was diagnosed months later and treated by mushroom catheter as described by Schoetz (2). The patient had satisfactory continence with five stools per day. She worked full-time and became pregnant again 40 months after closure of the diverting ileostomy. During her pregnancy the number of stools increased from five to nine per day and no drainage occurred through the fistulous tract. No complications occurred during pregnancy and a Caesarian section was performed after 37 weeks because of a placenta previa. She delivered a healthy boy of $2800 \mathrm{~g}$. Two months later the fistula became more symptomatic and repair was undertaken under diverting ileostomy coverage (2).

\section{DISCUSSION}

Although one of the patients who presented with toxic megacolon during pregnancy suffered a fetal death in utero, both were eventually able to deliver a healthy baby at term. A review of the literature on the issue of pregnancy with ulcerative colitis shows the following: ulcerative colitis, whether active or inactive, does not reduce fertility; the incidence of obstetrical complications is nearly the same as for the general population; $30 \%$ of women with inactive colitis at the time of conception will develop an exacerbation of their disease during pregnancy or puerperium, which does not differ from the rate at which ulcerative colitis recurs among nonpregnant woman of comparable age (exacerbations of the colitis, if there are any, tend to occur in the first trimester or at puerperium); if the disease is active at the time of conception, patients may be more likely to suffer spontaneous abortion, premature delivery or exacerbation of their colitis (3-6).

Although reports of ulcerative colitis during pregnancy are rather frequent, toxic megacolon occurs rarely during the course of pregnancy. A review of several cases shows that there is no unanimity in the management of this threatening condition $(1,7-12)$. The fetal mortality rate is as high as $71 \%$. Since the outcome of pregnancy depends greatly on overall maternal health, therapeutic management should be directed primarily towards the mother. The operative mortality rate of toxic megacolon in pregnancy is $21 \%$, which is slightly superior to the authors' operative mortality rate in cases without pregnancy, which is $11 \%$ (13). The decision to operate should not usually be postponed because of the gravid state.

Although immediate colectomy without any trial of medical treatment was advocated for all cases of toxic megacolon in pregnancy by Holzback in 1969 (1), 24 to $48 \mathrm{~h}$ of intensive medical treatment is also advocated ( 7 . 12). Two of 21 patients with toxic colonic dilation during pregnancy responded well to medical treatment, and gave birth to viable fetuses $(7,10)$. The reported success rate of medical treatment in the nongravid state is similar (13).

Almost all pregnant patients presenting with the syndrome of toxic megacolon in inflammatory bowel dis. ease should initially be subjected to intensive medical treatment. Some of these may respond favorably and will not require surgery. The remaining group should be monitored carefully and if no improvement is obtained with medical treatment within $48 \mathrm{~h}$, surgery is required. Extreme vigilance is required by the consulting surgeon because severe peritonitis may be masked by the high dose intravenous hydrocortisone therapy. The present authors' operation of choice is total colectomy without proctectomy. Care should be taken during the operation to place the ileostomy rather higher than usual since after pregnancy the site may descend. Leaving the rectum intact permits a 
later restoration of intestinal continuity by an ileoanal anastomosis with a pelvic reservoir.

Ileal pouch-anal anastomosis is compatible with a safe pregnancy and delivery. Although the first report led to the recommendation that delivery should be performed by Caesarian section to avoid damage to the sphincter mechanism in these patients (14), later reports stated that the majority of pregnant women with an ileal pouch could deliver vaginally with episiotomies $(15,16)$. In some cases the technique of episiotomy had to be modified to a mediolateral position as happened for case 1. For those who needed a Caesarian section, the most common indication was obstetrical, as seen in case 2 (16). Most patients with pelvic pouches had uncomplicated pregnancies. The complications that occurred in these patients were the same as occur in the general obstetrical population. Finally, in a study of 20 pregnant women with ileal pouches, Nelson and co-workers (16) showed that pregnancy caused a small increase in nocturnal stool frequency, which was also seen in the present two patients.

Medical treatment of toxic megacolon during pregnancy raises the important question of the potential effects of drugs on the fetus. Corticosteroids and sulphasalazine both cross the placenta in humans (17-19), and both sulphasalazine and sulfapyridine pass into breast milk $(17,18,20,21)$. However, there is little evidence that these drugs alter the outcome of pregnancy. Sulphasalazine preferentially binds to

ACKNOWLEDGEMENTS: This work was supported by the Health Research Foundation of the Pharmaceutical Manufacturers Association of Canada. The authors thank Linda Gagné for secretarial assistance.

\section{REFERENCES}

1. Holzback RT. Toxic megacolon in pregnancy. Am J Dig Dis 1969;14:908. 10.

2. Schoetz DJ, Coller JA, Veidenheimer MC. Can the pouch be saved? Dis Colon Rectum 1988;31:671-5.

3. Korelitz BI. Pregnancy, fertility and in- other sites on albumin than to the highaffinity binding site for bilirubin. The risk of kernicterus is then only theoretical or nonexistent in the full-term infant (20). Also, an important clinical study by Mogadam and co-workers (10) demonstrated that the use of corticosteroids and sulphasalazine in pregnancy associated with ulcerative colitis is unlikely to increase fetal morbidity or mortality. The medical prevention and treatment of toxic megacolon during the course of pregnancy should then follow the same prescriptions as for the nonpregnant patient.

It is worth noting that toxic megacolon is a serious complication not solely of ulcerative colitis, but also of Crohn's disease of the colon and, to a lesser extent, of ischemic colitis (13) and infectious colitis-like pseudomembranous colitis $(13,22)$, salmonellosis (13) or cryptosporidiosis (23). Sigmoidoscopic examination and fecal cultures will thus help establish the correct diagnosis and treatment. The pathogenesis of toxic dilation of the colon is related to the severe transmural inflammation which may damage the myenteric plexuses $(24,25)$. There is bacterial overgrowth and toxin production, and the diffusion of these products into the systemic circulation contributes to the toxic state (26). Several causal factors have been implicated as playing roles of variable importance in this complication including hypokalemia, barium enema, colonoscopy (27), opiates, anticholinergic drugs and/or antidiarrheal medication $(13,24)$. These factors were partially applicable in the present cases.

flammatory bowel disease. Am J Gastroenterol 1985;80:365-70.

4. Porter RJ, Stirrat GM. The effects of inflammatory bowel disease on pregnancy: A case-controlled retrospective analysis. Br J Obstet Gynaecol 1986;93:1124-31

5. Donaldson RM Jr. Management of medical problems in pregnancy - Inflammatory bowel disease. N Engl ] Med 1985;312:1616-9.

6. Miller JP. Inflammatory bowel disease in pregnancy: A review. J R Soc Med 1986;79:221-5.

7. Becker IM. Pregnancy and toxic dilatation of the colon. Am J Dig 1972;17:79. 84.
Some additional factors specifically associated with pregnancy could also play a role in colonic dilation, including tocolytic treatment with ritodrine $(1,28)$ or mechanical ileus caused by the association of an overdistended uterus and bed rest (28). A low hemoglobin level is common during pregnancy associated with inflammatory bowel diseases, and regular surveillance to exclude this may be advisable (4).

Hazards of radiography during preg. nancy may worry clinicians (29). Since the whole body of the fetus is likely to be irradiated, there is good reason for a special effort to limit radiographs involving the fetus if the results are not likely to affect management of the disease. However, the crucial examination in toxic megacolon is a plain abdominal $x$-ray $(12,24,30)$, and one must be prepared to perform it even in the gravid state. Protection of the fetus can be provided by shielding of the lower $a b$ domen.

In summary, this report deals with two pregnant women presenting with toxic megacolon. Both patients had an acute attack of ulcerative colitis at the beginning of their second trimester. They required subtotal colectomy and ileostomy. They subsequently underwent ileal pouch-anal anastomosis. Although one of the two infants died during the acute episode, both patients with a J-shaped ileal reservoir later carried a fetus to term. The clinical features and outcome of toxic megacolon during pregnancy were reviewed, and these two cases illustrate the favorable outcome of surgical treatment.

8. Bohe MG, Ekelund GR, Gennell SN, et al. Surgery for fulminating colitis during pregnancy. Dis Colon Rectum 1983;26:119.22.

9. Anderson JB, Turner GM, Williamson RCN. Fulminant ulcerative colit is in late pregnancy and the puerperium. JR Soc Med 1987; 80:492-4.

10. Mogadam M, Dobbins WO, Korelitz BI, Ahmed SN. Pregnancy in inflammatory bowel disease: Effect of sulfasalazine and corticosteroids on foetal outcome. Gastroenterology $1981 ; 80: 72-6$

11. Grant CS, Dozois RR. Toxic megacolon: Ultimate fate of patients after successful medical management. 
Am J Surg 1984;147:106-10.

12. Cooksey G, Gunn A, Wotherspoon WC. Surgery for acute ulcerative colitis and toxic megacolon during pregnancy. Br J Surg 1985;72:547.

13. Heppell J, Farkouh E, Dube S, Peloquin A, Morgan S, Bernard D. Toxic megacolon, an analysis of 70 cases. Dis Colon Rectum 1986;29:789-92.

14. Pezim ME. Successful childbirth after restorative proctocolectomy with pelvic ileal reservoir. $\mathrm{Br}$ ] Surg 1984:71:292.

15. Metcalf AM, Dozois RR, Beart RW Jr, Wolff BG. Pregnancy following ileal pouch-anal anastomosis. Dis Colon Rectum 1985;28:859-61.

16. Nelson H, Dozois RR, Kelly KA, Malkasian GD, Wolff BG, Ilstrup DM. The effect of pregnancy and delivery on the ileal pouch-anal anastomosis functions. Dis Colon Rectum 1989;32:384-8.

17. Azad Khan AK, Truelove SC. Placental and mammary transfer of sulphasalazine, Br Med J 1979;2:1553.

18. Hensleigh PA, Kauffman RE. Maternal absorption and placental transfer of sulfasalazine. Am J Obstet Gynecol 1977;127:443-4.

19. Jarnerot $\mathrm{G}$, Into-Malmberg M-B. Sulphasalazine treatment during breast feeding. Scand J Gastroenterol 1979;14:869-71.

20. Jarnerot G, Andersen S, Esbjorner E, Sandstrom B, Brodersen R. Albumin reserve for binding of bilirubin in maternal and cord serum under treatment with sulphasalazine. Scand J Gastroenterol 1981;16:1049-55.

21. Esbjorner $E$, Jarnerot $G, W$ ranne $L$. Sulphasalazine and sulphapyridine serum levels in children to mothers treated with sulphasalazine during preg. nancy and lactation. Acta Paediatr Scand 1987;76:137-42.

22. Burke GW, Wilson ME, Mehrez IO. Absence of diarrhea in toxic megacolon complicating Clostridium difficile pseudomembranous colitis. Am J Gastroenterol 1988;83:304-7.

23. Connely GM, Bazzard BG. Toxic megacolon in cryptosporidiosis. Postgrad Med ] 1987;63:1103-4.
24. Truelove SC, Marks CG. Toxic megacolon part 1: Pathogenesis, diag, nosis and treatment. In: Torsoli A, ed. Clinical Gastroenterology. London: WB Saunders, 1981;10:107-17.

25. McManus JP. The therapeutic dilemma of toxic megacolon. Gastroenterology 1985;89:1201-2.

26. Levin B. Ulcerative colitis. In: Wyngaarden JB, Lloyd HS, eds. Cecil's Textbook of Medicine, 18 th edn. Philadelphia: WB Saunders, 1988:755.

27. Reddy KR, Thomas E. Toxic megacolon after proctosigmoidoscopy in ulcerative colitis. South Med J 1983;76;1072-3.

28. Dan U, Rabinovici J, Koller M, Barkai $\mathrm{G}$, Mashiach S. latrogenic mechanical ileus due to over-distended uterus. Gynecol Obstet Invest 1988;25:143-4.

29. Mole RH. Irradiation of the embryo and foetus. Br J Radiol 1987;60:17-31.

30. Fazio VW. Toxic megacolon in ulcerative colitis and Crohn's disease. In: Farmer RG, ed. Clinical Gastroenterology. London: WB Saunders, 1980;9:389-407. 


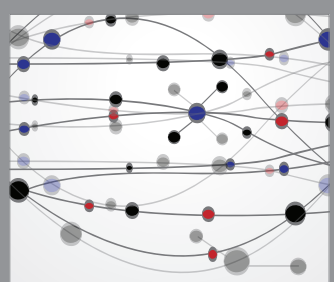

The Scientific World Journal
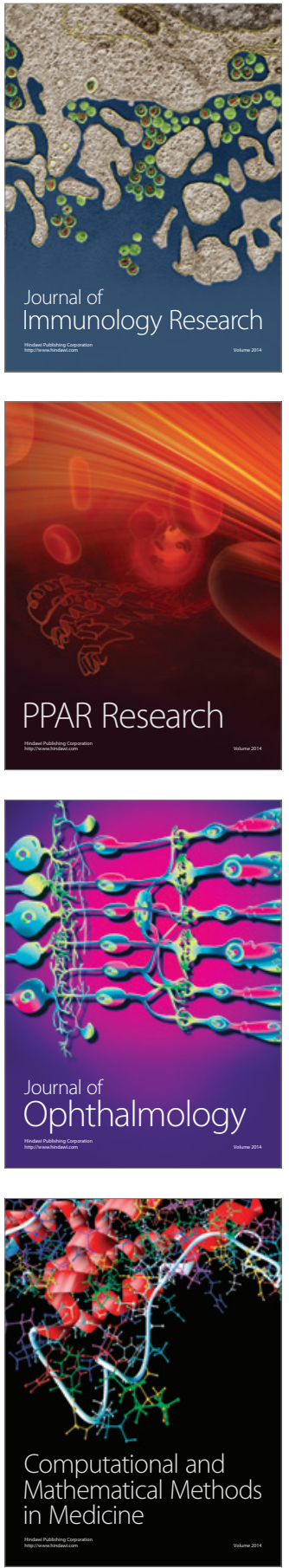

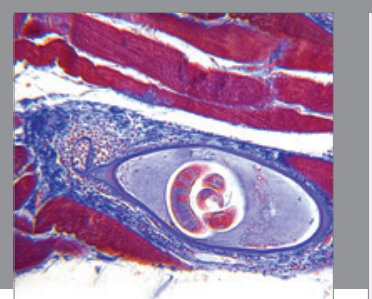

Gastroenterology Research and Practice

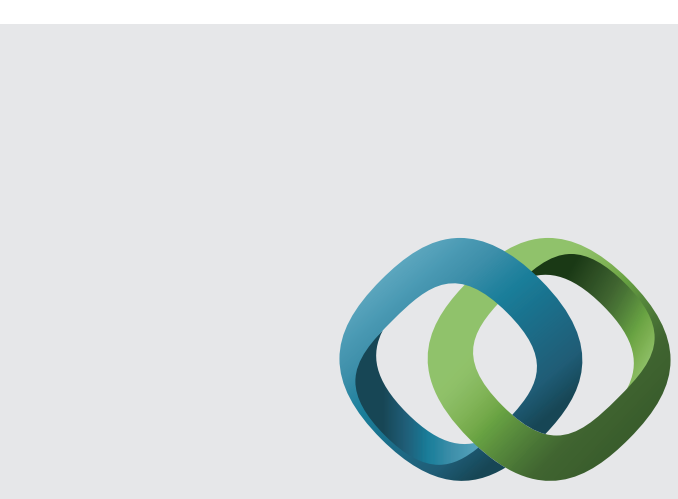

\section{Hindawi}

Submit your manuscripts at

http://www.hindawi.com
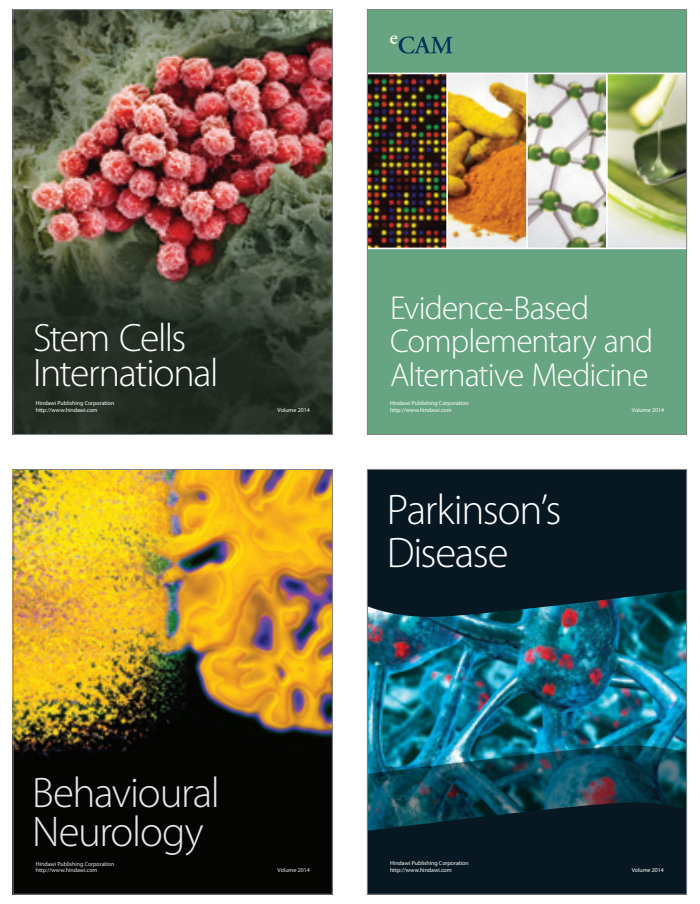
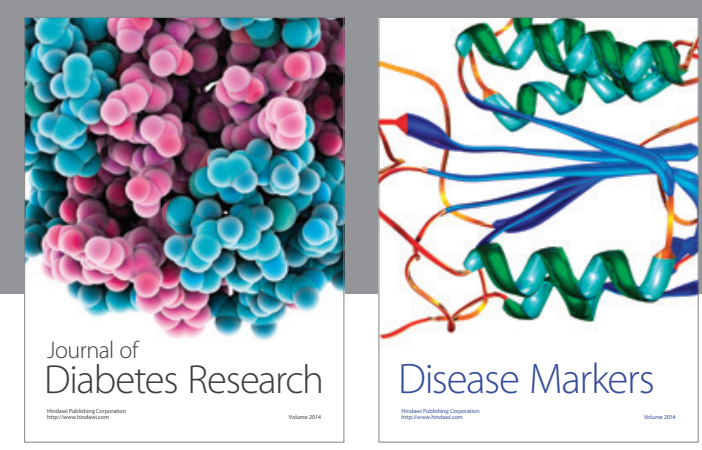

Disease Markers
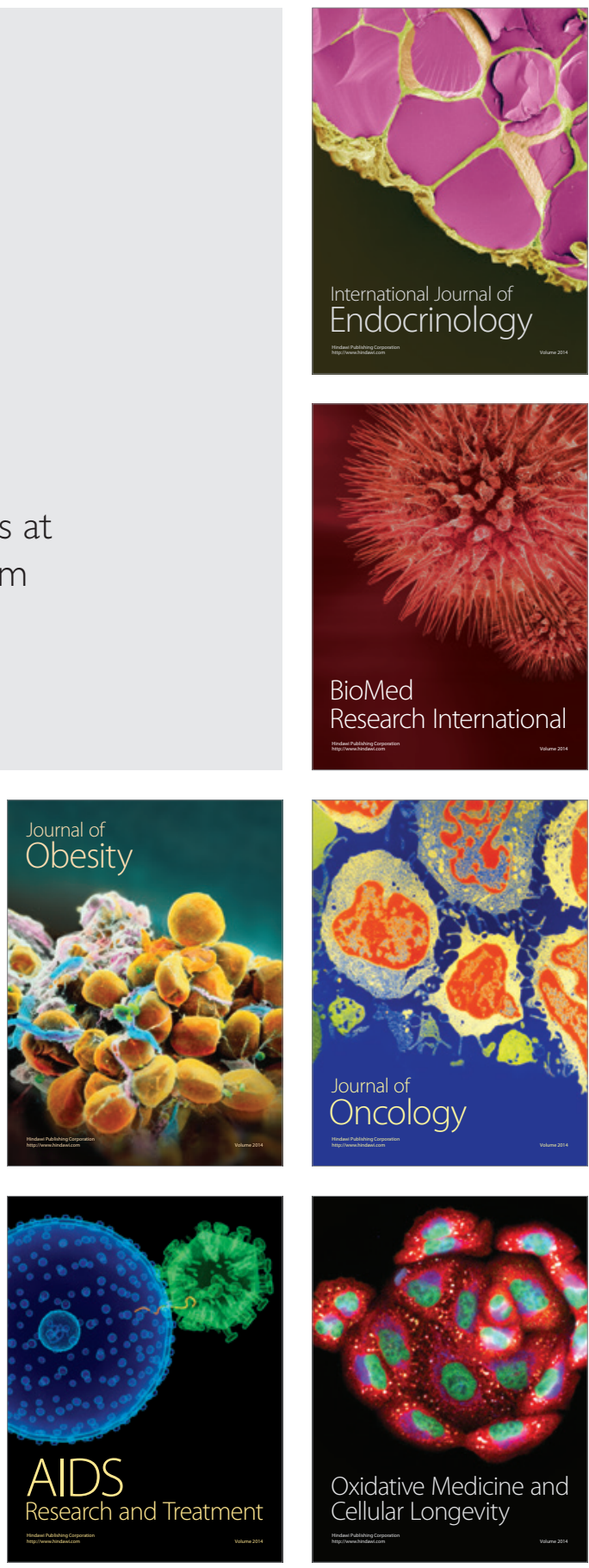